\title{
Asthma Masquerading as Chronic Obstructive Pulmonary Disease: A Study of Smokers Fulfilling the GOLD Definition of Chronic Obstructive Pulmonary Disease
}

\author{
Feisal A. Al-Kassimi ${ }^{\mathrm{a}}$ Abdullah A. Abba ${ }^{a}$ Mohammed S. Al-Hajjaj ${ }^{\mathrm{a}}$ \\ Esam H. Alhamad ${ }^{a}$ Emad Raddaoui $^{\mathrm{b}}$ Shaffi Ahamed Shaikh ${ }^{\mathrm{c}}$ \\ Departments of a Medicine, ${ }^{b}$ Pathology and ${ }^{\mathrm{C}}$ Family and Community Medicine, College of Medicine, \\ King Saud University, Riyadh, Saudi Arabia
}

\section{Key Words \\ Airway obstruction - Asthma - Bronchial biopsy \\ Chest CT • Chronic obstructive pulmonary disease • \\ Differential diagnosis - Global Initiative for Obstructive Lung Disease guidelines}

\begin{abstract}
Background: Irreversible airways obstruction in smokers is usually attributed to chronic obstructive pulmonary disease (COPD). We speculate that some of these are cases of asthma indistinguishable from COPD. Objectives: To determine the prevalence of asthma in a 'COPD' population and how to differentiate the two conditions. Methods: This was a prospective observational study of smokers fulfilling the Global Initiative for Chronic Obstructive Lung Disease definition of COPD [mean post-salbutamol forced expiratory volume in $1 \mathrm{~s}\left(\mathrm{FEV}_{1}\right) 66.9 \%$ predicted]. They were classified into 4 groups, as follows: (1) inhaled corticosteroid (ICS)-responsive asthma, defined by normalization of spirometry upon ICS treatment; (2) irreversible asthma, defined as airway obstruction for 1 year and bronchial biopsy indicating asthma; (3) COPD, in the presence of bilateral panlobular emphysema with bullae on high-resolution computed tomography, hypercapneic respiratory failure or bronchial biopsy indicating
\end{abstract}

COPD, and (4) unclassified airflow limitation (AFL). Results: Eighty patients fulfilled the definition of COPD. The initial diagnosis was COPD in $57.5 \%$ and asthma in $42.5 \%$. The final diagnosis was ICS-responsive asthma in 48 patients (60\%), irreversible asthma in $8(10 \%)$, COPD in $16(20 \%)$ and unclassified AFL in 8 (10\%). A normal transfer coefficient for carbon monoxide (KCO) and an $\mathrm{FEV}_{1}$ fluctuation $\geq 18 \%$ during 1 year of follow-up distinguished irreversible asthma and COPD. Seven of the 8 patients with irreversible asthma had improved $\mathrm{FEV}_{1}$ at the end of 1 year (median $320 \mathrm{ml}$ compared with $-29 \mathrm{ml}$ in COPD). Five out of the 8 unclassified AFL cases had normal $\mathrm{KCO}$ and a large improvement in $\mathrm{FEV}_{1}$ suggestive of irreversible asthma. Conclusions: COPD, even in heavy smokers, includes cases of asthma. FEV ${ }_{1}$ fluctuation during 1 year is a novel concept which may distinguish irreversible asthma and COPD.

Copyright $\odot 2011$ S. Karger AG, Basel

\section{Introduction}

Asthma and chronic obstructive pulmonary disease (COPD) are the commonest respiratory illnesses, with high morbidity. Misdiagnosing one condition as the other is not uncommon, especially in the elderly [1-3]. Bellia

\section{KARGER}

Fax +4161306 1234

E-Mail karger@karger.ch

www.karger.com
(C) 2011 S. Karger AG, Basel

0025-7931/11/0821-0019\$38.00/0

Accessible online at:

www.karger.com/res
Feisal A. Al-Kassimi

PO Box 94357

Riyadh 11693 (Saudi Arabia)

Tel. +966 1467 2386, Fax +96614672431

E-Mail falkassimi@yahoo.com 
et al. [2], in 2003, found that every fifth elderly asthmatic patient is misdiagnosed as having COPD. In another study on 25 patients labeled as having COPD, 12 were proven conclusively to be asthmatic [3]. Large studies have documented that diagnostic confusion between the two conditions is common [4] and that the label can be switched between COPD and asthma in the same patient [5]. The various guidelines on both sides of the Atlantic [e.g. Global Initiative for Chronic Obstructive Lung Disease (GOLD), National Institute for Health and Clinical Excellence, American Thoracic Society/European Respiratory Society] recognize the presence of irreversible asthma but do not offer conclusive means of differentiating it from COPD. The American Thoracic Society/European Respiratory Society guidelines stated in 2004 that 'some patients with asthma cannot be distinguished from COPD with the current diagnostic tests' [6]. More importantly, many authorities are still debating whether asthma and COPD are the same disease (the Dutch hypothesis) $[7,8]$. However, the landmark work of Fabbri et al. [9] on the histology of asthma and COPD has opened the way for reliable differentiation between the two conditions with the help of bronchial biopsy.

COPD (diagnosed by spirometry criteria), when it occurs in never-smokers, is attributed in $20-80 \%$ of cases to irreversible asthma. This is concluded mainly on the basis of a history of asthma, eosinophilia or significant reversibility of forced expiratory volume in $1 \mathrm{~s}\left(\mathrm{FEV}_{1}\right)[10$, 11]. The term airflow limitation (AFL) is used by some researchers to describe airway obstruction of unknown etiology.

On the other hand, COPD in smokers is usually attributed to genuine COPD (chronic bronchitis/emphysema). We speculate that even in smokers there must exist a significant number of cases of irreversible asthma masquerading as genuine COPD, given 2 facts: (1) over $20 \%$ of cases of asthma become irreversible $[12,13]$ and (2) smoking increases the risk of irreversible asthma [13].

Therefore, we decided to study a group of smoking patients who fulfill the GOLD definition for COPD in order to explore (1) the relative prevalence of COPD, irreversible bronchial asthma, unclassified AFL (not classified as either irreversible asthma or COPD) and inhaled corticosteroid (ICS)-reversible bronchial asthma in the group of smokers, (2) noninvasive criteria for differentiating COPD and irreversible asthma and (3) the rate of $\mathrm{FEV}_{1}$ decline in 1 year in irreversible asthma and COPD.

High-resolution computed tomography (HRCT) and bronchial biopsy were used as means of achieving the classification.

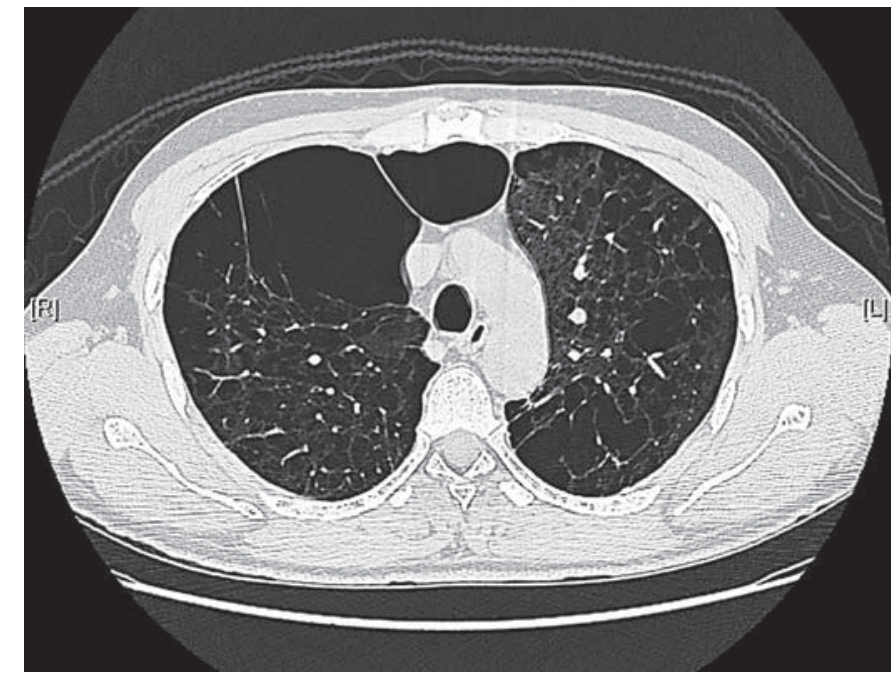

Fig. 1. Panlobular emphysema with bullae.

\section{Methods}

\section{Study Population}

This was a prospective observational study conducted between September 2007 and March 2009 at King Khalid University Hospital, Riyadh, Saudi Arabia. The study was approved by the Institutional Review Board of King Saud University, and all participants gave written informed consent. Patients attending the pulmonology clinics were screened, and those fulfilling the following criteria were enrolled in phase I of the study: smokers (>10 packs/year), age 40-70 years and labeled by their treating pulmonologist as having asthma or COPD. Exclusion criteria were bronchiectasis or left ventricular failure.

\section{Pulmonary Function Testing}

All patients underwent spirometry before and 15 min after inhaling $5 \mathrm{mg}$ of salbutamol by nebulizer. This is the standard practice in our institution as many elderly patients have difficulty with the meter dose inhaler technique. Patients with $\mathrm{FEV}_{1}$ /forced vital capacity $<70 \%$ and $\mathrm{FEV}_{1}<80 \%$ after salbutamol nebulization (GOLD stage II or worse) were enrolled for phase II. The patients were reviewed after 3 weeks and then every 2 months for 1 year with a repeat of pre- and post-salbutamol spirometry. Plethysmography and diffusing capacity for carbon monoxide $\left(\mathrm{DL}_{\mathrm{CO}}\right)$ were performed at 0,6 and 12 months. $\mathrm{DL}_{\mathrm{CO}}$ was divided by lung volume to obtain the transfer coefficient for carbon monoxide (KCO). All tests were performed at least 1 month after the last acute exacerbation, defined as any worsening of symptoms requiring a visit to a doctor or a change of regular medications. The tests were performed according to the recommendations of the American Thoracic Society.

Patient Follow-Up and Diagnostic Criteria

Patients on metered dose inhalers were tested for inhalation technique. All patients were started on budesonide $320 \mu \mathrm{g} /$ formoterol $9 \mu \mathrm{g}$ twice daily by Turbuhaler (Symbicort; AstraZeneca, 
Fig. 2. Flow diagram of diagnostic criteria. FVC = Forced vital capacity; LABA = longacting $\beta 2$-agonist.

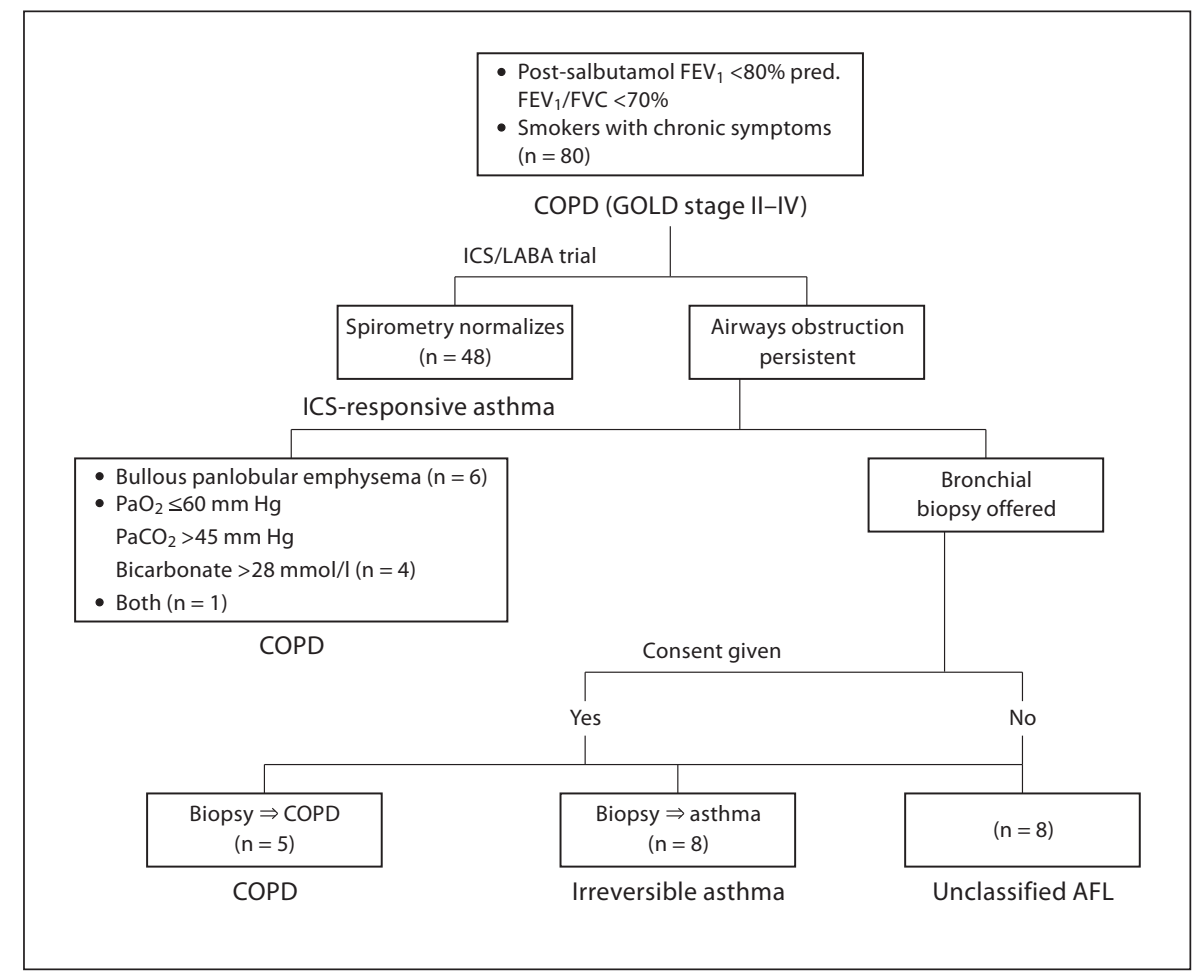

Sweden) after tuition. A plain chest X-ray and HRCT scan were ordered, and patients free from bullous panlobular emphysema or hypercapneic respiratory failure were offered an endobronchial biopsy taken by fiberoptic bronchoscopy from a 3rd-order bronchus. Hypercapneic respiratory failure was defined as $\mathrm{PaO}_{2}$ of 60 $\mathrm{mm} \mathrm{Hg}$ or less, $\mathrm{PaCO}_{2}>45 \mathrm{~mm} \mathrm{Hg}$ and bicarbonate $>28 \mathrm{mmol} / \mathrm{l}$. The accuracy of HRCT, hypercapneic respiratory failure and bronchial biopsy to distinguish COPD and irreversible asthma is described below in the Discussion.

Panlobular emphysema was defined as extensive areas of low attenuation without a well-defined wall that are evenly distributed throughout the lobule and associated with vascular and septal disruption. Bullae are diagnosed when several of these areas exceed $2 \mathrm{~cm}$ in diameter (fig. 1). Centrilobular and paraseptal emphysema, which occasionally occur in asthma, were not accepted as evidence for COPD.

Figure 2 is a flow diagram for the diagnostic criteria. The final diagnosis was made according to the following classification:

(1) ICS-responsive asthma if spirometry normalized with budesonide/formeterol at any time during follow-up;

(2) irreversible asthma if spirometry remained obstructive during follow-up in spite of budesonide/formeterol and the bronchial biopsy showed diffuse thickening of the reticular basement membrane of at least 6.6. $\mu \mathrm{m}$ (fig. 3);

(3) COPD in the presence of panlobular emphysema with bullae, hypercapneic respiratory failure or bronchial biopsy showing squamous metaplasia with epithelial/subepithelial inflammation and a basement membrane of $6.0 \mu \mathrm{m}$ or less (fig. 4), or

(4) unclassified AFL if the patient refused bronchial biopsy and continued to experience airway obstruction.

\section{Management of Patients}

All the patients in the study were managed as indicated by their clinical condition. It has been the practice in the first author's clinic to use HRCT scan and fiberoptic bronchial biopsy as means of differentiating irreversible asthma and COPD. The patients diagnosed with COPD were continued on budesonide/formoterol only if they had had frequent exacerbations ( 3 or more) in the previous year. Otherwise, anticholinergics were used instead.

\section{Statistical Analysis}

The data were entered in MS Excel and analyzed using the statistical software package SPSS PC+ version 13.0 (SPSS Inc., USA). Descriptive statistics, i.e. medians, interquartile range and range, were used to describe the study variables. Nonparametric statistical tests, i.e. the Mann-Whitney U test and Kruskal-Wallis test, were used to compare the median values across the categorical variables with 2 and 3 groups. The $\chi^{2}$ test was used to observe an association between categorical study and outcome variables. A $p$ value of $<0.05$ was considered statistically significant.

\section{Results}

As seen from table 1 , a total of 81 patients fulfilled the GOLD criteria for COPD (airway obstruction after salbutamol nebulization). One patient was lost to follow-up. All but 1 were male, and $70 \%$ had smoked 40 packs/year 
Table 1. Characteristics of the patients

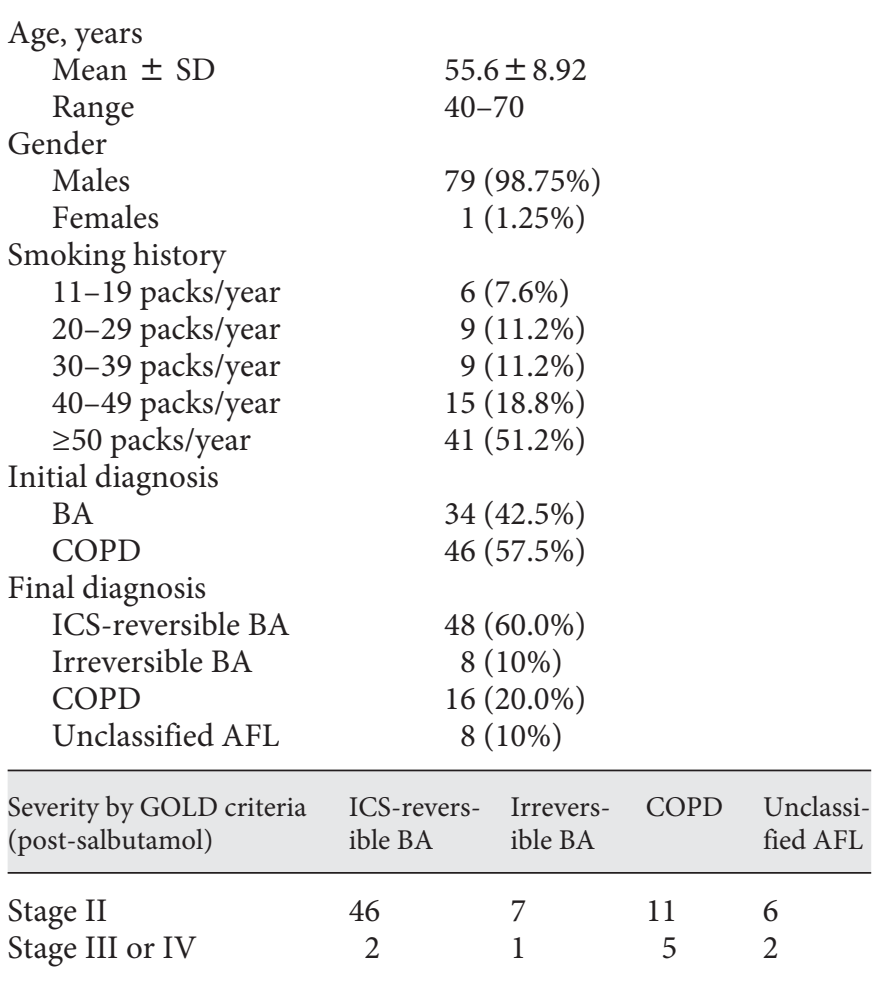

Figures represent numbers of patients, except where indicated otherwise. $\mathrm{BA}=$ Bronchial asthma.

Table 2. Pre- and post-salbutamol spirometry for our 80 patients

\begin{tabular}{|c|c|c|c|}
\hline & $\mathrm{FEV}_{1}, \mathrm{ml}$ & $\mathrm{FEV}_{1}, \%$ pred. & $\mathrm{FEV}_{1} / \mathrm{FVC}, \%$ \\
\hline $\begin{array}{l}\text { Pre- } \\
\text { salbutamol }\end{array}$ & $\begin{array}{l}1,909 \pm 503 \\
(844-2,849)\end{array}$ & $\begin{array}{l}61 \pm 9.8 \\
(32.7-76.2)\end{array}$ & $\begin{array}{l}63 \pm 4.6 \\
(52.9-68.9)\end{array}$ \\
\hline $\begin{array}{l}\text { Post- } \\
\text { salbutamol }\end{array}$ & $\begin{array}{l}2,098 \pm 581 \\
(890-3,150)\end{array}$ & $\begin{array}{l}66.9 \pm 11.4 \\
(32.9-78.1)\end{array}$ & $\begin{array}{l}65.7 \pm 4.8 \\
(53-69.9)\end{array}$ \\
\hline
\end{tabular}

Values are shown as means $\pm \mathrm{SD}$ (range).

$\mathrm{FVC}=$ Forced vital capacity.

or more. Table 2 gives the spirometry values before and after salbutamol. A total of 70 patients were stage II (moderately severe) and 10 were stage III or IV (severe or very severe) according to GOLD criteria. Treatment compliance was poor, as only 12 of $80(15 \%)$ were taking their medications regularly as prescribed; the rest were using their inhalers only once daily or as required. Moreover,

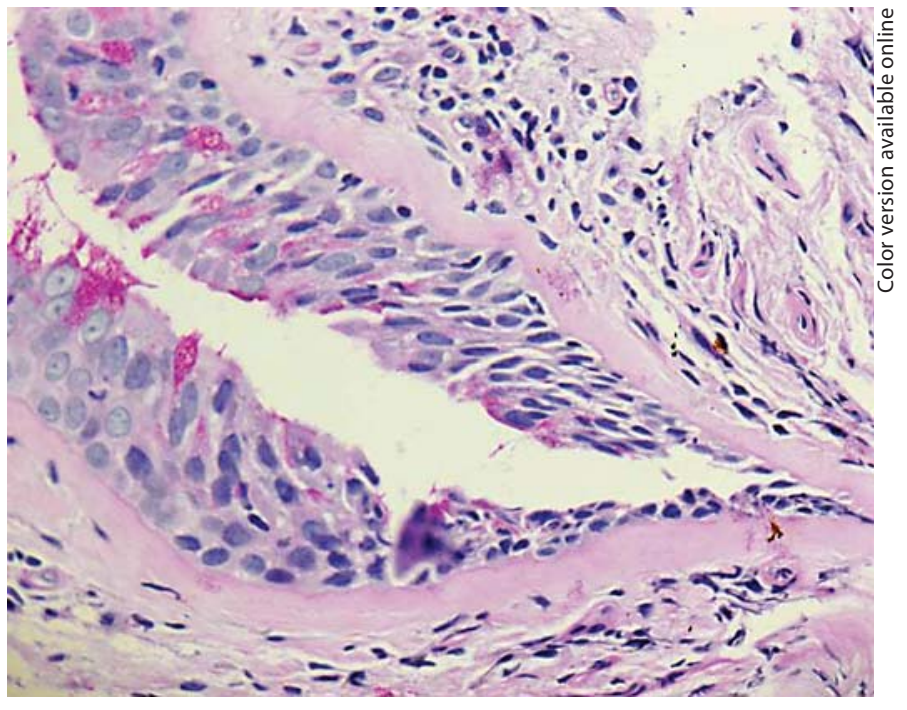

Fig. 3. Diffuse reticular basement membrane thickening in irreversible asthma. Periodic acid-Schiff stain. $\times 40$.

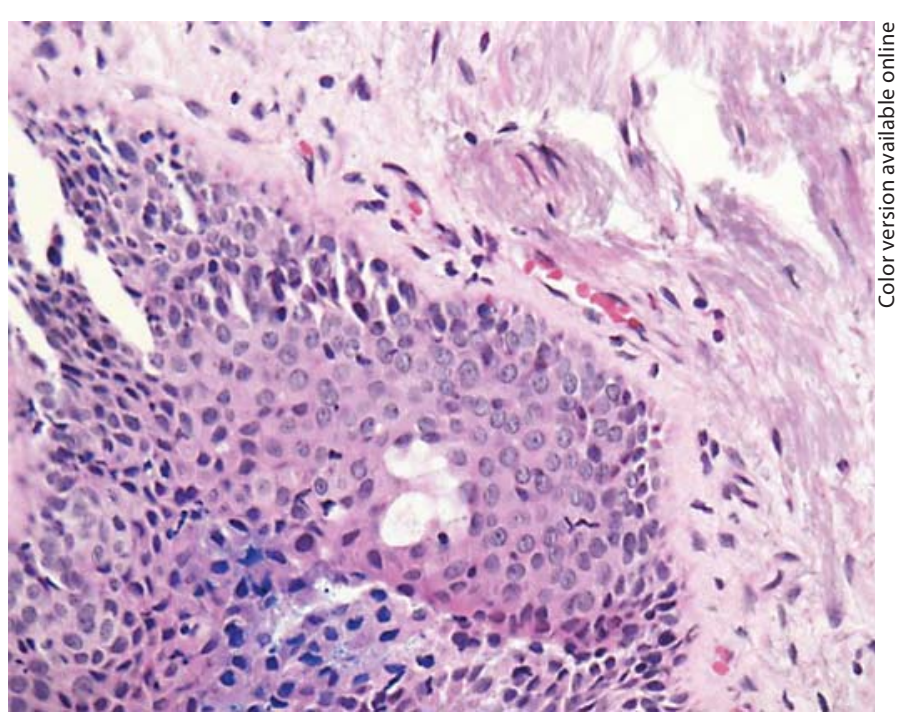

Fig. 4. Squamous metaplasia with epithelial/subepithelial inflammation without thickening of the reticular basement membrane in COPD.

all the patients on metered dose inhalers had serious problems with inhalation technique, namely lack of hand-breath coordination or shallow inhalation.

The initial diagnosis was bronchial asthma in $42.5 \%$ and COPD in $57.5 \%$. The final diagnosis was as follows: ICS-reversible asthma in 48 patients (60\%), irreversible asthma in 8 (10\%), COPD in $16(20 \%)$ and unclassified 
Table 3. Comparison of clinical characteristics and pulmonary function tests between 3 groups of patients

a Clinical characteristics

\begin{tabular}{lccc}
\hline Final diagnosis & $\begin{array}{l}\text { ICS-reversible BA } \\
(\mathrm{n}=48)\end{array}$ & $\begin{array}{l}\text { Irreversible BA } \\
(\mathrm{n}=8)\end{array}$ & $\begin{array}{l}\text { COPD } \\
(\mathrm{n}=16)\end{array}$ \\
\hline $\begin{array}{l}\text { Age, years } \\
\text { Smoking }\end{array}$ & $52(47-61)(40-70)$ & $52.5(44-56)(42-61)$ & $67.5(54-70)(49-70)$ \\
$\quad$ value
\end{tabular}

Values are shown as medians (interquartile range) (range) or numbers of patients (percentage), as appropriate. BA = Bronchial asthma.

${ }^{a}$ Kruskal-Wallis test. ${ }^{\mathrm{b}} \chi^{2}$ test.

b Pulmonary function tests

\begin{tabular}{|c|c|c|c|c|}
\hline & $\begin{array}{l}\text { ICS-reversible BA } \\
(\mathrm{n}=48)\end{array}$ & $\begin{array}{l}\text { Irreversible BA } \\
(\mathrm{n}=8)\end{array}$ & $\begin{array}{l}\text { COPD } \\
(n=16)\end{array}$ & $\begin{array}{l}\mathrm{p} \\
\text { value }\end{array}$ \\
\hline $\mathrm{KCO}, \%$ predicted & $\begin{array}{l}93.9(89-100.3) \\
(79-116)\end{array}$ & $\begin{array}{l}93.4(84-98.18) \\
(81.2-117.6)\end{array}$ & $\begin{array}{l}48.9(29.4-60) \\
(18.7-65.3)\end{array}$ & $<0.0001^{\mathrm{a}}$ \\
\hline Greatest fluctuation in $\mathrm{FEV}_{1}$ in 1 year, \% & - & $\begin{array}{l}29.4(22.8-40.95) \\
(18.1-50.5)\end{array}$ & $\begin{array}{l}13.85(9.73-15.1) \\
(5.7-17.4)\end{array}$ & $<0.0001^{\mathrm{b}}$ \\
\hline Change in $\mathrm{FEV}_{1}$ at the end of 1 year, $\mathrm{ml}$ & - & $\begin{array}{l}320.5(57.5 \text { to } 460) \\
(-260 \text { to } 500)\end{array}$ & $\begin{array}{l}-29(-48 \text { to } 45) \\
(-120 \text { to } 91)\end{array}$ & $0.007^{\mathrm{b}}$ \\
\hline
\end{tabular}

Values are shown as medians (interquartile range) (range). $\mathrm{BA}=$ Bronchial asthma.

${ }^{a}$ Kruskal-Wallis test. ${ }^{\mathrm{b}}$ Mann-Whitney U test.

AFL in 8 (10\%). The diagnosis of COPD was based on the following: bullous panlobular emphysema in 6 patients, hypercapneic respiratory failure in 4 , bullae plus respiratory failure in 1 and bronchial biopsy in 5 . Bronchial biopsy was performed in 13 patients. In the 8 patients with irreversible asthma, the mean basement membrane thickness was $7.76 \mu \mathrm{m}$ (range 6.6-8.7), compared with $4.86 \mu \mathrm{m}$ (range 3.7-5.9) in the 5 patients whose COPD was diagnosed by biopsy. The COPD patients had, in ad- dition, squamous metaplasia with epithelial/subepithelial inflammation.

Table 3a compares the clinical characteristic of 3 groups (ICS-reversible asthma, irreversible asthma and COPD) based on final diagnosis. Patients with COPD were significantly older than those with ICS-reversible bronchial asthma and irreversible asthma. All COPD patients had smoked 50 packs/year or more, but heavy smoking was also found with bronchial asthma. The on- 
Table 4. Characteristics of the undiagnosed AFL group

\begin{tabular}{lllll}
\hline $\begin{array}{l}\text { Age } \\
\text { years }\end{array}$ & $\begin{array}{l}\mathrm{FEV}_{1} \text { after 3 weeks } \\
\text { of ICS/LABA } \\
\text { \% predicted }\end{array}$ & $\begin{array}{l}\text { KCO } \\
\text { \% pre- } \\
\text { dicted }\end{array}$ & $\begin{array}{l}\mathrm{FEV}_{1} \text { fluctua- } \\
\text { tion during } \\
\text { follow-up, \% }\end{array}$ & $\begin{array}{l}\text { Change in FEV } \\
\text { at the end } \\
\text { of 1 year, ml }\end{array}$ \\
\hline 54 & 63 & 86 & 18 & 350 \\
55 & 75 & 89 & 40 & 480 \\
45 & 67 & 87 & 32 & 600 \\
60 & 43 & 92 & 21 & 260 \\
60 & 53 & 95 & 29 & 320 \\
53 & 78 & 51 & 11 & -19 \\
60 & 47 & 46 & 16 & -44 \\
70 & 56 & 55 & 7 & 35 \\
\hline
\end{tabular}

LABA = Long-acting $\beta 2$-agonist.

set of wheeze or shortness of breath was late in COPD; these 2 symptoms appeared in our COPD patients at age 40 or older. Allergic rhinitis and hypertrophy of nasal turbinates were significantly associated with reversible and irreversible asthma, but were occasionally present with COPD. None of the clinical features could differentiate the 3 conditions.

As seen in table $3 \mathrm{~b}, \mathrm{KCO}$ differentiated fully between COPD and irreversible asthma. Irreversible asthma showed much greater levels of fluctuation of $\mathrm{FEV}_{1}$ and maximum expiratory flow at $50 \%$ of vital capacity in 1 year than COPD. Only the fluctuation of $\mathrm{FEV}_{1} \%$ in 1 year distinguished irreversible asthma from COPD; a level of fluctuation of $18 \%$ or more occurred in all asthmatics and none in COPD. At the end of the 1-year follow-up, 7 of the 8 patients with irreversible asthma had increased their $\mathrm{FEV}_{1}$ (median $320 \mathrm{ml}$ ). In the majority of COPD patients (12/16), $\mathrm{FEV}_{1}$ had deteriorated (median change $-29 \mathrm{ml}$ ), although only 2 of the 16 patients were still smoking.

Table 4 gives the characteristics of the undiagnosed AFL group. It is clear that the group is heterogenous and likely to contain both COPD and irreversible asthma cases. The first 5 patients had normal KCO and wider fluctuations of $\mathrm{FEV}_{1}$ during follow-up than the asthmatics (above 18\%), and all showed improvements in $\mathrm{FEV}_{1}$ at the end of follow-up (range 260-600 ml). The last 3 patients had low KCO and less fluctuation of $\mathrm{FEV}_{1}$ in 1 year, and their $\mathrm{FEV}_{1}$ declined or rose very little (range -44 to $35 \mathrm{ml}$ ).

Although the two subgroups of patients with unclassified AFL behaved physiologically like irreversible asthma and COPD, we cannot conclusively ascribe a diagnostic label to them.

\section{Discussion}

This paper describes a simple clinical scheme aimed at elucidating the nature of cases of salbutamol-irreversible airways obstruction (fulfilling the GOLD definition of COPD). In spite of an abundance of publications on the role of HRCT scan and bronchial histopathology in differentiating COPD and asthma, there is surprisingly little use of these methods. The various guidelines on both sides of the Atlantic do not advocate their use in the differentiation of COPD from irreversible asthma.

Although many studies have documented that asthma and COPD have distinct bronchial pathologies, these studies suffered from the drawback that they compared old COPD patients with young patients with reversible asthma and concluded that the bronchial biopsy is not sufficiently discriminatory [14]. The paper of Fabbri et al. [9] in 2003 was a landmark, as it compared COPD with 'fixed' (irreversible) asthma in patients with an average age of 65 years. They concluded that in those groups, the two conditions are distinguishable pathologically. Thickening of the reticular basement membrane - the hallmark of chronic asthma - is associated with airway remodeling and irreversible asthma; studies in that group have documented the usefulness of basement membrane measurement $[9,15,16]$. In the paper of Fabbri et al. [9], the basement membrane in irreversible asthma was 6.6$9.7 \mu \mathrm{m}$, and in COPD, it was 4.2-6.2 $\mu \mathrm{m}$ [9]. Other pathological features, e.g. $\mathrm{CD}_{4} / \mathrm{CD}_{8}$ ratio, unlike thickness of the reticular basement membrane, showed an overlap between irreversible asthma and COPD [9]. Based on the work of Fabbri et al. [9] and others and our own observations, the most reliable and reproducible sign for asthma is uniform thickening of the reticular basement membrane of $6.6 \mu \mathrm{m}$ or more $[9,15,16]$, and for COPD, a basement membrane of $6 \mu \mathrm{m}$ or less in addition to squamous metaplasia with epithelial/subepithelial inflammation $[9$, 15]. All our patients with irreversible asthma (diagnosed by biopsy) had normal KCO and significant reversibility of $\mathrm{FEV}_{1}$, features that were absent in those patients diagnosed histologically as having COPD.

Large studies on patients receiving long-term oxygen for chronic respiratory failure in Italy and Poland included no asthmatics, and the commonest indication was COPD $[17,18]$. Although hypercapnea with acidosis is common in acute severe asthma attacks, we found no reports of chronic hypercapnea with raised bicarbonate in stable asthma. We found a report where some elderly (average age $79 \pm 1.2$ years) Japanese subjects with irreversible asthma (average $\mathrm{FEV}_{1} 55 \pm 0.5 \%$ predicted) required 
home oxygen therapy [10]. Even in that extreme group (in terms of age and $\mathrm{FEV}_{1}$ ), the alveolar-arterial gradient for oxygen was only $22.1 \pm 1.6 \mathrm{~mm} \mathrm{Hg}$, and $\mathrm{PaO}_{2}$ was 76.9 $\pm 1.7 \mathrm{~mm} \mathrm{Hg}$. It is not mentioned why those patients required home oxygen and whether it was used intermittently for asthma exacerbations or continuously [10].

HRCT cannot always differentiate asthma from COPD, as mild emphysema has occasionally been reported in asthma $[19,20]$. However, the emphysema associated with asthma is usually centrilobular or paraseptal and not panlobular $[19,20]$. In the largest series of asthmatics (160 patients), 7.9\% of patients had centrilobular or paraseptal emphysema, but no panlobular emphysema were detected by HRCT scan [19]. This contrasts with COPD, where about 1 in 3 patients displays panlobular emphysema [21]. By limiting our definition of COPD to bullae, which are the ultimate form of panlobular emphysema, we were confident that we did not inadvertently include any asthmatics. Other researchers have not reported panlobular emphysema in asthma even when it is severe or near fatal $[20,22]$. Computerized emphysema scores were not used, as they cannot differentiate the type of emphysema. Computerized scores also have the drawback of failing to exclude bronchiectasis, a condition common in Saudi Arabia. Even in industrialized countries, bronchiectasis is common as an alternative or concomitant diagnosis in COPD $[23,24]$.

Out of 80 smoking patients in our study with salbutamol-irreversible airways obstruction (fulfilling the GOLD spirometric definition of COPD), 34 were labeled as asthmatic and 46 as COPD by their consultant. We concluded that $48(60 \%)$ had ICS-reversible asthma, 16 (20\%) had COPD, 8 (10\%) had irreversible asthma and 8 (10\%) had unclassified AFL. The trend for overdiagnosis of COPD was related to missing ICS-reversible asthma (poor metered dose inhaler technique and compliance) and genuine irreversible bronchial asthma. Although it is well known that misdiagnosis of asthma and COPD is common, the problem was thought to occur mostly in the elderly $[1,2]$. There are no reliable data on the percentage of misdiagnosed cases. Bellia et al. [2] estimated in 2003 that every fifth elderly asthmatic is misdiagnosed as having COPD.

An earlier study that used bronchial biopsy found that out of 25 patients labeled as having COPD, 12 showed thickening of the basement membrane and displayed significant reversibility of obstruction after prednisolone [3]. This contrasts with our data, where of the 32 patients who remained obstructive after an ICS/long-acting $\beta 2$ agonist trial, 8 had irreversible asthma (with another 5 in the unclassified AFL group likely to be the same). Although irreversible asthma has been repeatedly reported for over 35 years, studies as recent as 2009 label it neversmokers COPD [10]. The latter study found that the great majority of the never-smokers COPD subjects (all elderly) had received a physician diagnosis of asthma or had clinical features of asthma [10]. Published reports indicate that over $20 \%$ of asthma cases become irreversible [12, 13]. This is attributed to airway remodeling in longstanding asthma [25]. Long duration of asthma, frequent exacerbations, onset in adulthood and smoking are some of the factors associated with fixed airway obstruction in asthma $[12,13,26]$. Therefore, smokers are at risk for developing not only COPD but also irreversible asthma. In a paper by Boulet et al. [27] that compared 14 patients with irreversible asthma (without significant smoking history) and a similar number of patients with COPD, $\mathrm{DL}_{\mathrm{CO}}$ was normal in all irreversible asthma cases. These findings are similar to our data. However, in line with other studies, the patients with irreversible asthma in the study of Boulet et al. [27] had no significant smoking history. The present study shows that even in moderate and heavy smokers, irreversible asthma is distinguishable from COPD by displaying greater reversibility of $\mathrm{FEV}_{1}$ $(>18 \%)$ during a 1-year follow-up, normal KCO and histological features of asthma.

None of the guidelines offers a clear-cut spirometric differentiation between COPD and irreversible asthma $[6,28,29]$. Lack of reversibility is essential to the diagnosis of COPD, but the definition of reversibility varies between continents (US, British, European), resulting in wide variability in the spirometric diagnosis of COPD [30]. Single reversibility tests have consistently failed to distinguish asthma from COPD [31]. The highest sensitivity (55\%) and specificity (91\%) for asthma were obtained when the percentage increase in post-bronchodilator $\mathrm{FEV}_{1}$ in relation to the predicted $\mathrm{FEV}_{1}$ were greater than $10 \%$ [32]. However, the criteria for diagnosing asthma and COPD were based on the clinical impression of pulmonologists and were not objectively confirmed [32].

In our study, all cases of COPD had a smoking history of 50 packs/year or more. This is higher than reported in other series; the difference may be attributed to the fact that only 1 of our patients was a female, who are known to be more susceptible to COPD. Also, other series may have inadvertently included patients with irreversible asthma. Our asthmatics (whether reversible or irreversible) were younger than the COPD patients. However, age was no bar to developing any of the 3 conditions. We confirm the previous reports that worsening symptoms on 
exposure to fumes or cats does not differentiate asthma and COPD [33].

The highest fluctuation of $\mathrm{FEV}_{1}$ in 1 year (outside exacerbations) of $18 \%$ or more was associated with irreversible asthma, while all COPD patients had lower fluctuation. Reversibility can be expressed in various ways, and we selected year-long reversibility, as spirometry is known to vary longitudinally [34].

KCO distinguished fully irreversible asthma and COPD. Several studies have shown that $\mathrm{DL}_{\mathrm{CO}}$ remains normal or raised in asthma, even when severe [12, 27, 35]. The situation with COPD is less clear, with conflicting results on the sensitivity and specificity of $\mathrm{DL}_{\mathrm{CO}}[36,37$. The discrepancy may be related to the fact that $\mathrm{DL}_{\mathrm{CO}}$ remains normal in early COPD but declines considerably with advanced disease [37]. All our COPD cases were stage II or more, which could explain the uniformly low KCO. It is interesting that all the studies that used objective methods for diagnosing COPD, whether HRCT scanning or bronchial biopsy, found that $\mathrm{DL}_{\mathrm{CO}}$ correlated with COPD [9, 38]. In the study of Fabbri et al. [9] on the histology of irreversible asthma and COPD, the average $\mathrm{DL}_{\mathrm{CO}}$ was 85 and $65.4 \%$ predicted, respectively.

Studies going back to the 1970 s used the a priori assumption that if $\mathrm{DL}_{\mathrm{CO}}$ or $\mathrm{DL}_{\mathrm{CO}} /$ alveolar volume is low, emphysema is diagnosed, and if normal, chronic bronchitis is diagnosed $[39,40]$. However, pathological studies have demonstrated that emphysema and bronchitis can coexist and that 'pink puffer' and 'blue bloater' do not represent a major difference in the severity of emphysema $[41,42]$. This may explain why in our study and in the series of Fabbri et al. [9], $\mathrm{DL}_{\mathrm{CO}}$ was low in all cases of COPD even though the bronchial biopsy demonstrated clear changes of bronchitis. Moreover, the biological markers in induced sputum are the same in both phenotypes of COPD [43].

\section{Limitations of Our Study}

The relatively small number of cases of COPD and irreversible asthma prevents us from reaching conclusive findings, especially on the role of $\mathrm{KCO}$ and $\mathrm{FEV}_{1}$ fluctuation in 1 year in distinguishing the two conditions. Larger studies are needed.

\section{Conclusions}

Even in smokers, COPD as defined by the GOLD criteria includes many cases of ICS-reversible and irreversible asthma. HRCT and bronchial biopsy appear to be useful as part of the investigation of the COPD patient in selected cases. Further larger studies are needed to validate that irreversible asthma can be distinguished from genuine COPD by the novel concept of wide fluctuation of $\mathrm{FEV}_{1}$ on follow-up for 1 year and normal KCO. The diagnosis of unclassified AFL - if widely adopted - can be useful in spurring on the search for a specific diagnosis.

\section{Acknowledgements}

We would like to acknowledge the assistance given by $\mathrm{Mr}$. Amir Marzouk with the entering of the data and compiling the results. AstraZeneca's representatives supplied a few hundred Symbicort inhalers, most of which were used to supplement gaps in the pharmacy's supplies. Uninterrupted use of the drug during the follow-up was assured.

\section{References}

1 Lindner K, Panaszek B, Machaj Z: Asthma in the elderly (in Polish). Pol Arch Med Wewn 2007;8:350-354.

2 Bellia V, Battaglia S, Catalano F, et al: Aging and disability affect misdiagnosis of COPD in elderly asthmatics: the SARA study. Chest 2003;123:1066-1072.

3 Chanez P, Vignola AM, O'Shaugnessy T, et al: Corticosteroid reversibility in COPD is related to features of asthma. Am J Respir Crit Care Med 1997;155:1529-1534.

4 Diagnosis of airway obstruction in primary care in the UK: the CADRE (COPD and Asthma Diagnosis/management REassessment) programme 1997-2001. Int J Chron Obstruct Pulmon Dis 2006;1:435-443.
5 Shaya FT, Dongyi D, Akazawa MO, et al: Burden of concomitant asthma and COPD in a Medicaid population. Chest 2008; $134: 14-$ 19.

6 Celli BR, MacNee W; ATS/ERS Task Force: Standards for the diagnosis and treatment of patients with COPD: a summary of the ATS/ ERS position paper. Eur Respir J 2004;23: 932-946.

7 Kraft M: Asthma and chronic obstructive pulmonary disease exhibit common origins in any country! Am J Respir Crit Care Med 2006;174:238-240.
8 Barnes PJ: Against the Dutch hypothesis: asthma and chronic obstructive pulmonary disease are distinct diseases. Am J Respir Crit Care Med 2006;174:240-243.

9 Fabbri LM, Romagnoli M, Corbetta L, et al: Differences in airway inflammation in patients with fixed airflow obstruction due to asthma or chronic obstructive pulmonary disease. Am J Respir Crit Care Med 2003;167: 418-424.

10 Tsuda Y, Nogochi T, Mochizuki H, et al: Patients with mild-to-moderate asthma may develop clinically significant chronic obstructive pulmonary disease. Respirology 2009;14:529-536. 
-11 Hudon C, Turcotte H, Laviolette M, et al: Characteristics of bronchial asthma with incomplete reversibility of airflow obstruction. Ann Allergy Asthma Immunol 1997; 78:195-202.

-12 Ulrick CS, Backer V: Nonreversible airflow obstruction in life-long nonsmokers with moderate to severe asthma. Eur Respir J 1999; 14:892-896.

13 ten Brinke A: Risk factors associated with irreversible airflow limitation in asthma. Curr Opin Allergy Clin Immmunol 2008;8:63-69.

14 Bourdin A, Serre I, Flamme A, et al: Can endobronchial biopsy analysis be recommended to discriminate between asthma and COPD in routine practice? Thorax 2004;59: 488-493.

15 Ollerenshaw SL, Woolcock AJ: Characteristics of the inflammation in biopsies from large airways of subjects with asthma and subjects with chronic airflow limitation. Am Rev Respir Dis 1992;145:922-927.

16 Bourdin A, Neveu D, Vachier I, et al: Specificity of basement membrane thickening in severe asthma. J Allergy Clin Immunol 2007; 119:1367-1374.

17 Caramori G, Fabbri M, Paioli D, et al: Asth$\mathrm{ma}$ is not a common cause of severe chronic respiratory failure in non-smokers: ALOT study. Monaldi Arch Chest Dis 2005;63:8487.

18 Szafranski W, Polsce JZ: Long-term domiciliary oxygen therapy (LTOT) in Poland in the years 1986-2005 (in Polish). Pneumonol Alergol Pol 2007;75:331-342.

19 Harmanci E, Kebapci M, Metintas M, et al: High-resolution computed tomography findings are correlated with disease severity in asthma. Respiration 2002;69:420-426.

20 Lee YM, Park JS, Hwang JH, et al: High-resolution CT findings in patients with nearfatal asthma: comparison of patients with mild-to-severe asthma and normal control subjects and changes in airway abnormalities following steroid treatment. Chest 2004; 126:1840-1848.

-21 Gupta PP, Yadav R, Verma M, et al: High-resolution computed tomography features in patients with chronic obstructive pulmonary disease. Singapore Med J 2009;50:193-200.
22 Teel GS, Engeler CE, Tashijian JH, et al: Imaging of small airways disease. Radiographics 1996;16:27-41.

23 O'Brien C, Guest P, Hill S, Stockley R: Physiological and radiological characterisation of patients diagnosed with chronic obstructive pulmonary disease in primary care. Thorax 2000;55:635-642.

24 Patel IS, Vlahos I, Wilkinson TM, et al: Bronchiectasis, exacerbation indices, and inflammation in chronic obstructive pulmonary disease. Am J Respir Crit Care Med 2004; 170:400-407.

25 ten Hacken NH, Postma DS, Timens W: Airway remodeling and long-term decline in lung function in asthma. Curr Opin Pulm Med 2003;9:9-14.

26 Backman KS, Greenberger PA, Patterson R, et al: Airways obstruction in patients with long-term asthma consistent with 'irreversible asthma'. Chest 1997;112:1234-1240.

27 Boulet LP, Turcotte H, Hudon C, et al: Clini$\mathrm{cal}$, physiological and radiological features of asthma with incomplete reversibility compared with those of COPD. Can Respir J 1998;5:270-277.

28 Global Initiative for Chronic Obstructive Lung Disease: Global strategy for the diagnosis, management, and prevention of chronic obstructive pulmonary disease: updated 2007. http://www.goldcopd.org/.

29 NHLBI/WHO: Global initiative for chronic obstructive lung disease. Bethesda, National Institutes of Health, National Heart, Lung, and Blood Institute, 2001; NIH Publication Number 2701.

30 Reid DW, Soltani A, Johns DP, et al: Bronchodilator reversibility in Australian adults with chronic obstructive pulmonary disease. Intern Med J 2003;33:572-577.

31 Chhabra SK: Acute bronchodilator response has limited value in differentiating bronchial asthma from COPD. J Asthma 2005;42:367372.

32 Silvestri IC, de Castro Pereira CA, Rodrigues SCS: Comparison of spirometric changes in the response to bronchodilators of patients with asthma or chronic obstructive pulmonary disease. J Bras Pneumol 2008;34:675682 .
3 Tinkelman DG, Price DB, Nordyke RJ, et al: Symptom-based questionnaire for differentiating COPD and asthma. Respiration 2006; 73:296-305.

34 Calverley PM, Burge PS, Spencer S, Anderson JA, Jones PW: Bronchodilator reversibility testing in chronic obstructive pulmonary disease. Thorax 2003;58:659-664.

35 Mitsunobu F, Mifune T, Ashida K, et al: Influence of age and disease severity on high resolution CT lung densitometry in asthma. Thorax 2001;56:851-856.

36 Magnussen H, Richter K, Taube C: Are chronic obstructive pulmonary disease (COPD) and asthma different diseases? Clin Exp Allergy 1998;28S:187-194.

37 Goedhart DM, Zanen P, Lammers JW: Relevant and redundant lung function parameters in discriminating asthma from COPD. COPD 2006;3:33-39.

38 Cerveri I, Dore R, Corsico A, et al: Assessment of emphysema in COPD: a functional and radiologic Study. Chest 2004;125:17141718.

39 Izquierdo JL, Almonacid C, Parra T, Pérez J: Systemic and lung inflammation in 2 phenotypes of chronic obstructive pulmonary disease (in Spanish). Arch Bronconeumol 2006; 42:332-337.

40 Openbrier DR, Irwin MM, Rogers RM, et al Nutritional status and lung function in patients with emphysema and chronic bronchitis. Chest 1983;83:17-22.

41 Mitchell RS, Stanford RE, Johnson JM, et al: The morphologic features of the bronchi, bronchioles, and alveoli in chronic airway obstruction: a clinicopathologic study. Am Rev Respir Dis 1976;114:137-145.

42 Cosio Piqueras MG, Cosio MG: Disease of the airways in chronic obstructive pulmonary disease. Eur Respir J 2001;34:41s-49s.

43 Bartoli ML, Franco AD, Vagaggini B: Biological markers in induced sputum of patients with different phenotypes of chronic airway obstruction. Respiration 2009;77: 265-272. 